\title{
OPTIMUM CONDITIONS FOR DIFFERENTIAL SAR INTERFEROMETRY TECHNIQUE TO ESTIMATE HIMALAYAN GLACIER VELOCITY
}

\author{
Bala Raju Nela $^{1,}{ }^{*}$, Gulab Singh $^{1}$, Anil V. Kulkarni ${ }^{2}$ and Kapil Malik ${ }^{3}$ \\ ${ }^{1}$ Centre of Studies in Resources Engineering, IIT Bombay, Mumbai - India - (balaraju, gulab.singh)@iitb.ac.in \\ ${ }^{2}$ Divecha Centre for Climate Change, IISC, Bangalore, Karnataka - India - anilkulkarni@iisc.ac.in \\ ${ }^{3}$ Dept. of Mining Engineering, IIT (ISM) Dhanbad, Jharkhand - India - kapil@me.ism.ac.in
}

Commission V, SS: Natural Resources Management

KEY WORDS: SAR, DInSAR, glacier zones, glacier movement and Coherence.

\begin{abstract}
Differential SAR Interferometry (DInSAR) is the process of differencing two Interferograms for measuring surface movement with an accuracy of millimeter range. The DInSAR process can be applied to observe glacier movement, earthquake deformations, volcanic activities and rate of subsidence or uplift caused due to the extraction of groundwater or coal. By using single pass interferometry technique we can also generate accurate DEM. In this paper, we are presenting the movement of a Chhota Shigri glacier with the help two pass DInSAR technique and mainly we concentrated on the optimum conditions for estimating glacier movement using DInSAR. We got good coherence and Interferogram fringes for L-band sensor with less temporal baseline. Therefore, we generated glacier velocity using ALOS-2 data with 14 days temporal baseline. Initially, we generated Interferogram (defo-pair) by taking 10th March 2015 image as a master and 24 th March 2015 image as a slave. But this generated Interferogram also having topographic information and atmospheric errors with the displacement component. Therefore, we used SRTM DEM for removing topographic information from the Interferogram. Because we are using L-band data, results may not be affected by troposphere. Maximum glacier velocity we observed in the accumulation zone as $7.285 \mathrm{~cm} /$ day in the month of March and while it's moving towards ablation zone the glacier velocity is decreasing.
\end{abstract}

\section{INTRODUCTION}

Glacier is one of the important components in the cryosphere to check climate and temperature changes. The cryosphere is the surface on earth where the liquid is available in solid form. Glacier forms due to the compaction and recrystallization snow in accumulation zone. Due to it's own weight, pressure and slope it will move from accumulation to ablation zone (mountainous areas). Glacier movement is mainly dependent on a slope, ice thickness, surrounding climate temperatures and it's bed surface. Glacier velocity is the amount of glacier flow due to its own weight and gravity for a particular period of time. Monitoring of glacier velocity is important because it gives information about the health of a glacier, ice thickness and also information about glacier hazards. Glacier movement can be monitored either field based or remote sensing based techniques. Field based techniques are very difficult, spatially limited and cost efficient, but results are accurate if we use Differential Global Positioning System (DGPS). In remote sensing techniques, microwave data is more useful to monitor glaciers due to it's penetration capability. We used 2-pass Differential Interferometric Synthetic Aperture Radar technique to measure glacier movement. Goldstein et al., (1993) [1] first time used satellite radar interferometry (SRI) technique to monitor the velocity of the ice sheet. We tested with different wavelength bands of microwave region like $\mathrm{X}(3 \mathrm{~cm}), \mathrm{C}(5.6 \mathrm{~cm})$ and $\mathrm{L}(24 \mathrm{~cm})$-bands to check optimum condition for glacier velocity estimation. We observed high coherence for L-band than $\mathrm{C}$ and $\mathrm{X}$ bands due to high wavelength (L-band of $23 \mathrm{~cm}$ ). We used ALOS-2 L-band data with 14 days temporal baseline to monitor Chhota Shigri glacier in the month of March 2015.

\section{DIFFERENTIAL SAR INTERFEROMETRY (DINSAR)}

Massonnet et al., (1993) [2] and Zebker et al., (1994) [3] applied the two pass differential interferometry and three pass differential interferometry for the first time. DinSAR uses the phase information present in the SAR images to precisely estimate the movement or displacement of a particular target point between two SAR images. Coherence gives an information about the correlation between two SAR images in the DInSAR process and it's range is from 0 to 1 . If the coherence value is 1 , then there is no change in the target point between master and slave images. Glacier movement can be estimated by using Interferometry technique by using any one of these three techniques [4].

1. If the baseline between two sensors is zero, then we can directly get the glacier movement by generating a single interferogram. But no InSAR system is planned like this.

2. 2 Pass DInSAR is used to estimate glacier movement with the help of an external DEM to remove topographic phase from the generated interferogram by using two SAR images.

3. 3 Pass DInSAR generates two interferograms, one is Defo-pair and another one is Topo-pair. Glacier velocity can be estimated by subtracting these two interferograms without using an external DEM

\footnotetext{
* Corresponding author
} 


\section{STUDY AREA AND DATASETS}

Chhota Shigri glacier is located in Chandra basin with 32.2218 lat and 77.5132 lon, in Himachal Pradesh. The length of the glacier is $9.2 \mathrm{~km}$ and it's area is around $15.01 \mathrm{~km}^{2}[5]$.

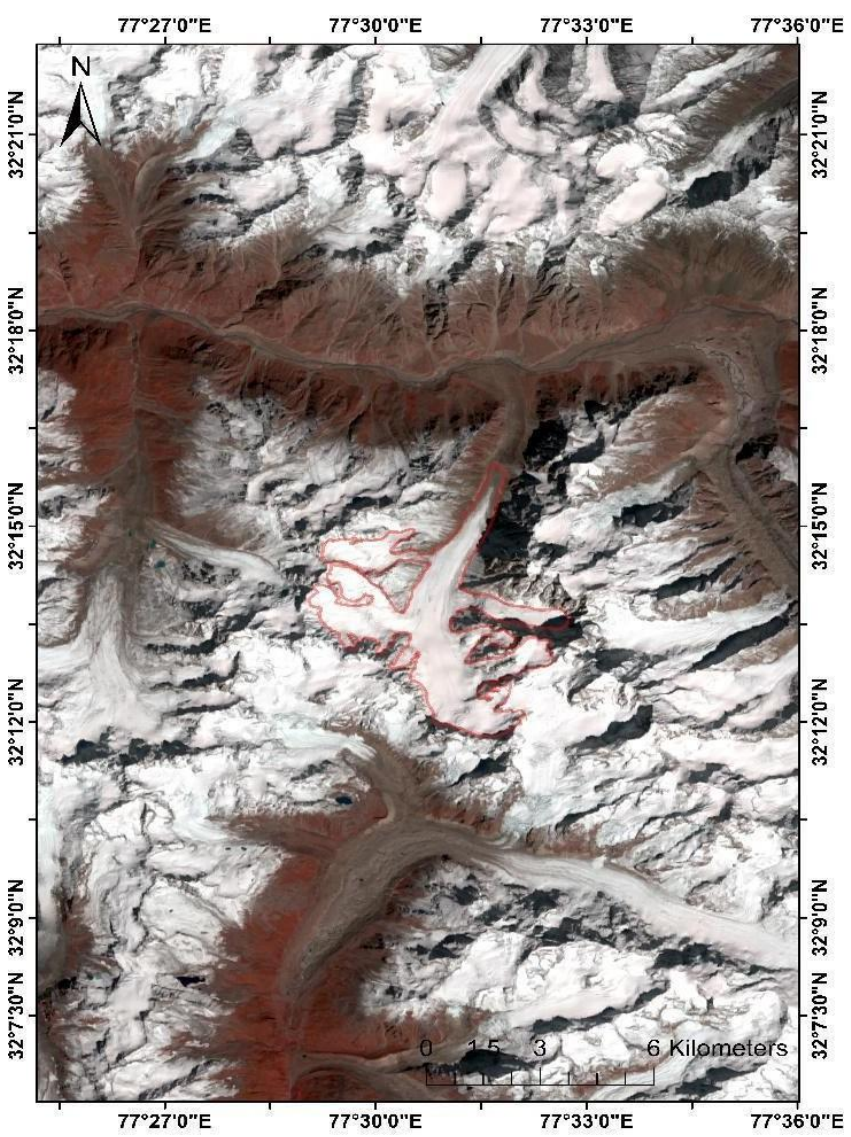

Figure 1. Location map of a study area. Chhota Shigri glacier boundary shown by the red polygon is overlain on False Color Composition (FCC) of Landsat image.

To find optimum conditions for glacier studies we used X, C and Lband datasets with different temporal baselines. For estimating Chotta Shigri glacier velocity we used ALOS-2 L-band satellite data with 14 days temporal gap and other important parameters are given in table.1. SRTM DEM is used to remove topographic phase information from the generated interferogram.

\section{METHODOLOGY}

We selected ALOS-2 satellite data with 14 days temporal baseline for avoiding decorrelation effect to use the DInSAR technique. Table. 1 giving the information about interferometric parameters for selected master and slave SLC images.

\begin{tabular}{|l|l|l|l|}
\hline Date & $\begin{array}{l}\text { Incident } \\
\text { angle } \\
\text { (deg) }\end{array}$ & $\begin{array}{l}\text { Temporal } \\
\text { Baseline } \\
\text { (days) }\end{array}$ & $\begin{array}{l}\text { Perpendicular } \\
\text { Baseline } \\
(\mathbf{m})\end{array}$ \\
\hline $10 / 03 / 2015$ & 31.402 & 0 & 0.00 \\
\hline $24 / 03 / 2015$ & 31.402 & 14 & -125.598 \\
\hline
\end{tabular}

Table 1. Details of selected master and slave image pair for the 2pass DInSAR process.

Initially, we coregistered master and slave images using Cross Correlation algorithm for subpixel level matching and then we generated interferogram by subtracting the phase information. This interferogram consists of displacement, topography and atmospheric errors. For generating velocity map we need to remove information other than displacement. Because we are using L-band data phase component due to tropospheric effect is very less. Topographic phase component is removed by using SRTM 1-arcsec DEM (30 m Resolution). Finally, differential interferogram having the displacement component only, but this phase is wrapped in between $(-\pi,+\pi)$. For recovering original phase information (unwrapped phase) we need to do phase unwrapping. Then, we converted this unwrapped phase into displacement by using below equation.

$$
\Delta \mathrm{R}=(-\lambda / 4 \pi) \Delta \phi
$$

Where $\Delta \mathrm{R}$ : Displacement in LOS direction

$$
\begin{aligned}
& \Delta \phi: \text { Unwrapped phase } \\
& \lambda \text { : Wavelength }
\end{aligned}
$$

This displacement can convert into movement in LOS direction by using the temporal gap between two SAR images (master and slave images).

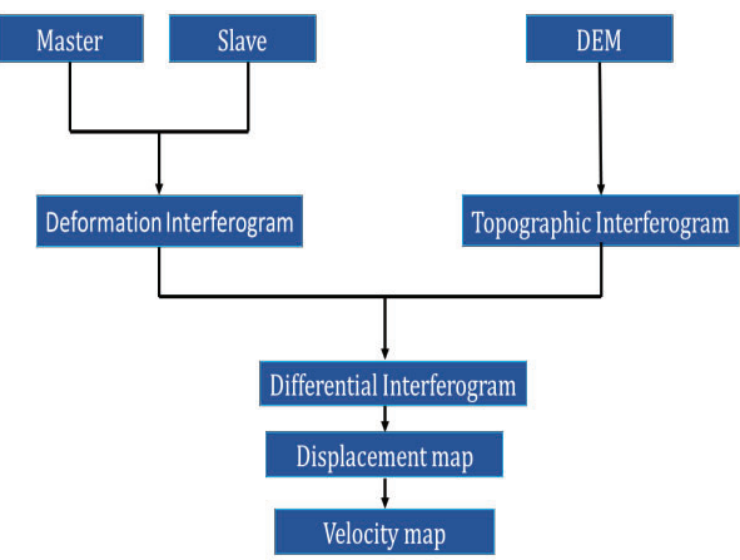

Figure 2. Flowchart for 2-pass DInSAR process 


\section{RESULTS AND DISCUSSION}

To find optimum conditions we used X, C and L-band satellite data. For DInSAR, selection of image pair is very important to continue the whole process to get accurate velocity results. For glacier movement, it's much more important to choose an appropriate pair. When we tested with these three different bands data, we clearly observed that coherence is low for the shorter wavelength data

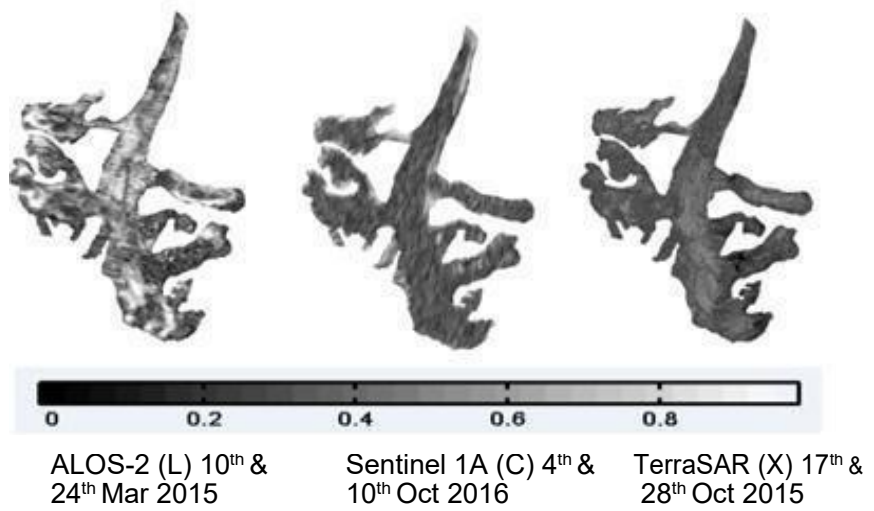

Figure 3. Comparison of decorrelation effect in coherence images due to wavelength and temporal baseline. Coherence range is from 0 to 1 .

Fig. 3 showing three coherence images of a Chhota Shigri glacier. First coherence image is generated by using ALOS-2 L-band satellite data of wavelength nearly $24 \mathrm{~cm}$ and 14 days temporal gap, second coherence image is generated by using Sentinel C-band satellite data of wavelength is nearly $5.4 \mathrm{~cm}$ and 6 days temporal gap and third coherence image is generated by using TerraSAR X-band satellite data of wavelength is nearly $3 \mathrm{~cm}$ and 11 days temporal gap. Here, we can see the decorrelation effect in $\mathrm{C}$ and $\mathrm{X}$-band coherence images (most of the pixels having the coherence value less than 0.4 ) compared to the L-band coherence image (most of the pixels having the coherence value greater than 0.8 ). Therefore, it's better to select L-band for using DInSAR technique to estimate glacier movement. We have also tested with different temporal baselines. We observed the low coherence for the pair of high temporal baseline.

After observing these optimum conditions for glacier movement we selected ALOS-2 L-band data with 14 days temporal baseline pair for the DInSAR process. We followed the methodology shown in fig. 2 for generating glacier velocity map. After phase unwrapping, we converted phase information into displacement in LOS direction by using equation (1). Velocity map was generated for Chhota Shigri glacier in the month of March 2015 in the LOS direction. In the fig. 4 , positive and negative signs are showing the direction of glacier movement in LOS direction. Here, negative sign indicating the glacier movement is away from the satellite and positive sign is indicating that the glacier movement is towards the satellite. We estimated the maximum velocity of a Chhota Shigri glacier as 7.285 $\mathrm{cm} /$ day or $26.59 \mathrm{~m} / \mathrm{yr}$ in LOS direction at the accumulation zone. From this glacier velocity map, we can also estimate the glacier ice thickness by using a Laminar flow equation [6]. From Laminar flow law, glacier ice thickness is directly proportional to the velocity.

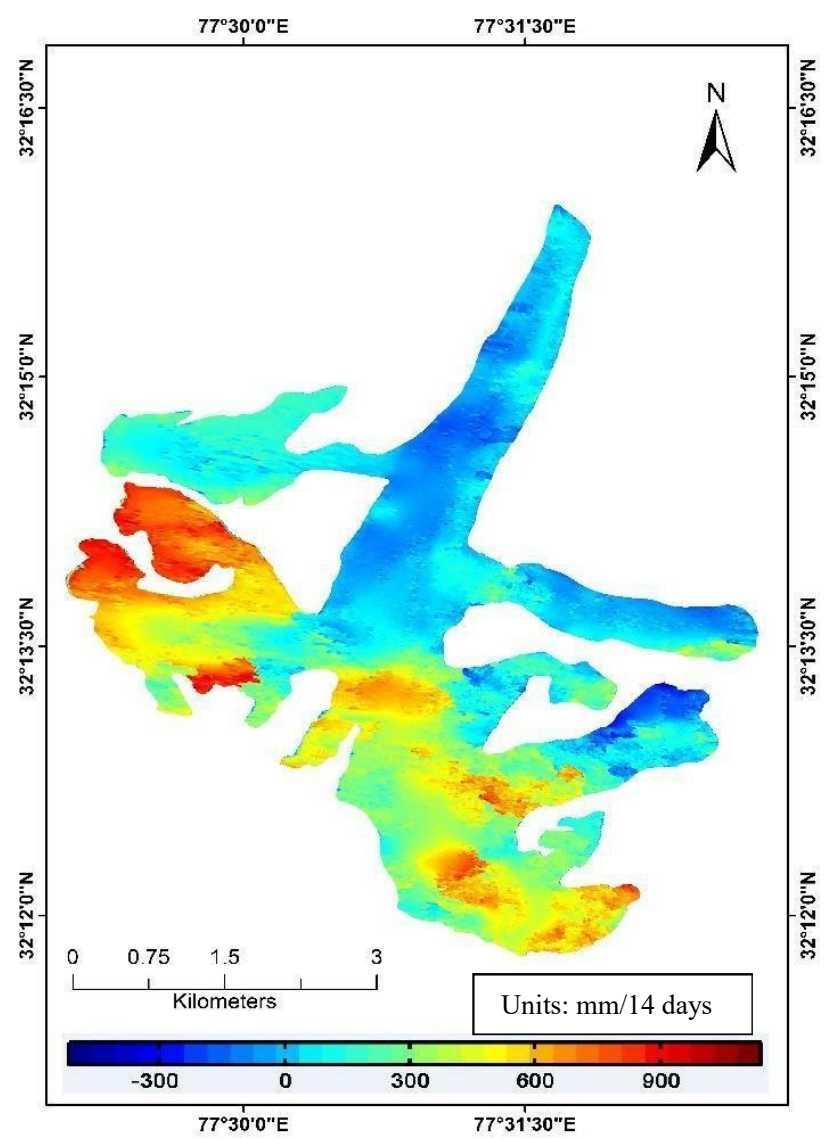

Figure 4. Velocity map of a Chhota Shigri glacier in Line of Sight (LOS) direction.

\section{CONCLUSION}

We also processed some glaciers in Chandra basin, Himachal Pradesh using the DInSAR technique with different SAR sensor data. We clearly observed that, high wavelength (L-band) and low temporal baseline of SAR images giving fewer decorrelation effects and better interferograms to continue the process for estimating glacier velocity. Now the working L-band SAR sensor is ALOS-2 with 14 days revisit time. Therefore, for glacier velocity estimation using the DInSAR technique, it's better to use ALOS-2 L-band data with the minimum temporal baseline. We estimated Chhota Shigri glacier velocity by using 2 pass DInSAR technique and we observed that the maximum velocity as $26.59 \mathrm{~m} / \mathrm{yr}$ in LOS direction at the accumulation zone and its decreasing towards the ablation zone.

\section{ACKNOWLEDGMENTS}

The authors would like to thank JAXA, DLR and ESA for providing the ALOS -2, TerraSAR-X and Sentinel-1 datasets to find optimum condition for glacier studies using SAR data. We are wholeheartedly thankful to SARPROZ team for giving an evaluation version to complete this work successfully. 


\section{REFERENCES}

[1] Goldstein, R. M., Engelhardt, H. E., Kamb, B., Frolich, R. M., 1993. Satellite radar interferometry for monitoring ice sheet motion: Application to Antarctic ice stream. Science, Vol. 262, pp. $1525-1530$.

[2] Massonnet, D., Marc Rossi, Carmona, C., Adragna, F., Peltzer, G., Feigl, K., Rabaute, T., 1993. The displacement field of the Landers earthquake mapped by radar interferometry. Nature, Vol. 364, pp. 138-142.

[3] Zebker, H. A., Rosen, P. A., Goldstein, R. M., Gabriel A., Werner, C. L., 1994. On the derivation of coseismic displacement fields using differential radar interferometry: The Landers earthquake. Journal of Geophysical Research, Vol. 99, pp. 19617-19634.

[4] Petri, K.E., and Rees, W.G., 2010. Remote sensing of glaciers, Taylor \& Francis Group, London.

[5] Sangewar, C.V., Shukla, S.P., 2009. Inventory of the Himalayan Glaciers. Geological Survey of India, Special Publication No. 34, pp. 588.

[6] Cuffey, K.M., and Paterson, W.S.B., 2010. The physics of glacier, Elsevier, USA. 